\title{
Bacterial cellulose to reinforce urethrovesical anastomosis. A translational study ${ }^{1}$
}

Guilherme Tavares da Silva Maia', Amanda Vasconcelos de Albuquerque", Euclides Dias Martins Filho"', Filipe Tenório de Lira Neto'v, Veridiana Sales Barbosa de Souzav, Anderson Arnaldo da Silva ${ }^{\mathrm{VI}}$, Mariana Montenegro de Melo LiravII, Salvador Vilar Correia Lima VIII

'Master, Urology Service, Clinical Hospital, Department of Surgery, Center for Health Sciences, Universidade Federal de Pernambuco (UFPE), Recife-PE, Brazil. Acquisition of data, technical procedures, manuscript preparation.

"PhD, Nucleus of Experimental Surgery, Postgraduate Program in Surgery, Department of Surgery, Center for Health Sciences, UFPE, Recife-PE, Brazil. Manuscript preparation, critical revision.

I'IPhD, Abdominal Surgery, Clinical Hospital, Department of Surgery, Center for Health Sciences, UFPE, Recife-PE, Brazil. Critical revision.

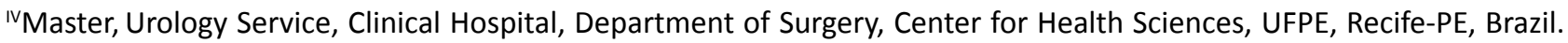
Technical procedures, critical revision.

vMaster, Nucleus of Experimental Surgery, Postgraduate Program in Surgery, Department of Surgery, Center for Health Sciences, UFPE, Recife-PE, Brazil. Technical procedures, manuscript preparation.

V'Master, Nucleus of Experimental Surgery, Postgraduate Program in Surgery, Department of Surgery, Center for Health Sciences, UFPE, Recife-PE, Brazil. Macroscopic and histopathological examinations

VIIPhD, Department of Pathology, Center for Health Sciences, UFPE, Recife-PE, Brazil. Macroscopic and histopathological examinations

VIIIMaster, Urology Service, Clinical Hospital, Department of Surgery, Center for Health Sciences, UFPE, Recife-PE, Brazil. Critical revision.

\section{Abstract}

Purpose: To evaluate the efficacy of the cellulosic exopolysaccharide membrane (CEM) as a urethral reinforcement for urethrovesical anastomosis.

Methods: Twenty eight rabbits were submitted to urethrovesical anastomosis with or without CEM reinforcement. The animals were divided into 4 groups: C7, CEM7, C14 and CEM14: (C= only anastomosis or CEM = anastomosis + CEM), evaluated after 7 weeks, and 14 weeks. The biointegration and biocompatibility of CEM were evaluated according to stenosis, fistula, urethral wall thickness, urethral epithelium, rate of inflammation and vascularization.

Results: Between the two experimental groups, the difference in the number of stenosis or urinary fistula was not statistically significant. The morphometric analysis revealed preservation of urethral lumen, well adhered CEM without extrusion, a controlled inflammatory process and implant vascularization. The urothelium height remained constant over time after CEM reinforcement and the membrane wall was thicker, statistically, after 14 weeks.

Conclusion: The absence of extrusion, stenosis or urinary fistula after 14 weeks of urethrovesical anastomosis demonstrates cellulosic exopolysaccharide membrane biocompatibility and biointegration with tendency to a thicker wall.

Key words: Anastomosis, Surgical. Prostatectomy. Biopolymers. Rabbits. 


\section{Introduction}

According to international data, it is estimated that about 600.000 new cases of cancer occurred in Brazil in 2017; of which about 61.000 were of prostatic origin ${ }^{1}$. Part of these cases will have had, as the main treatment, a radical prostatectomy ( $\mathrm{RP})$, which aims to cure the cancer and concomitantly maintain urinary continence and erectile function.

Since the urinary tract needs to be reconstructed after RP, urethrovesical anastomosis has become the most complex stage because it depends directly on the surgeon's skills, the type of material available and the technique used ${ }^{2}$. With the advent of robotic laparoscopic techniques and special sutures, anastomosis is increasingly-successful, with extremely low rates of stenosis or urinary fistula. However, some situations such as RP after transurethral resection of prostate (TURP) or radiotherapy require previous urethral reinforcement to prevent these complications and/or the use of an artificial sphincter to restore urinary continence in the future ${ }^{3}$ with poor overall outcomes. We assess another treatment option. Methods: A retrospective analysis was performed of 8 patients presenting with severe, recurrent incontinence after multiple prior failed AUS procedures. All patients were treated with small intestinal submucosa (SIS.

The quality and variety of materials for this purpose seem to be scarce and sometimes controversial. In this scenario, recent experimental and clinical studies have registered the successful performance of the cellulosic exopolysaccharide membrane (CEM), also known as sugarcane biopolymer ${ }^{4-7}$. CEM has recently been used in urethral reinforcement in rats and demonstrated to be biocompatible and integrated into the host tissue after adhering to the urethra ${ }^{8}$. We believe that this membrane could be used to reinforce urethrovesical anastomosis, since it results in minor tissue reaction and acts as a physical barrier, making the urethra more resistant. Because it is a product from an abundant raw material grown in our region, CEM presents lower cost and easier production when compared to the materials used on the market to promote urethral reinforcement. This project aims to evaluate the efficacy of the use of the CEM as a reinforcement in urethrovesical anastomosis, through histological and morphometric analysis.

\section{- Methods}

This study followed the principles governing the Code of Experimental Ethics and Laws for Protection of Animals, according to the standards in Brazil, receiving full approval from the Ethics Committee on Animal Experimentation of the Center for Biosciences, UFPE (process No 23076.009626/20113-26). The study was conducted by The Nucleus for Experimental Surgery of Federal University of Pernambuco - UFPE. Twenty-eight male rabbits were submitted to urethrovesical anastomosis. The animals were divided into 4 groups: Group C7: Anastomosis + 7-week postoperative analysis; CEM7: Anastomosis + CEM and 7-week analysis; C14 and CEM14 for 14-week analysis (Figure 1).

\section{Experimental Design}

Twenty eight rabbits ( $n=28$ ), New Zealand lineage, male and healthy. Groups: control anastomosis versus anastomosis with CEM reinforcement.

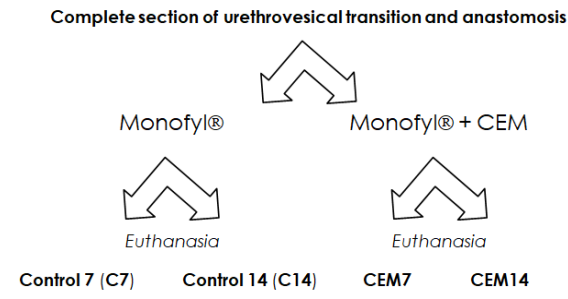

Figure 1 - Experimental design. 


\section{Surgical technique and cellulosic} exopolysaccharide membrane (CEM)

The animals were placed on the operating table in the supine position. Antisepsis of the abdominal wall was performed with chlorhexidine solution. A 6FR urethral catheter was used to facilitate urethral dissection, section and anastomosis. An abdominal midline incision of $\pm 5 \mathrm{~cm}$ was made. Access to that abdominal cavity was performed by the sequential dissection of anatomical planes. The bladder and urethra were then exposed. Using dissecting scissors, a small sub-urethral space $( \pm 6 \mathrm{~mm})$ was created just below the bladder neck to facilitate passage through the urethrovesical junction.
The urethra was sectioned at this point. The anastomosis was performed with Monofyl ${ }^{\circ}$ Poly (Control group). In the CEM group, the anastomosis was coated with a self-adhesive of cellulosic exopolysaccharide membrane (CEM) (Figure $2 \mathrm{~A}-\mathrm{D}$ ).

The CEM used in our study is a bacterial exopolysaccharide made by bacterial synthesis from sugarcane molasses. It was produced in a project developed at one of the institutions involved in the project (UFRPE) ${ }^{9}$. Each CEM implant was $4 \times 0.6 \mathrm{~cm} \times 0.04 \mathrm{~mm}$ thick and with $1.0 \mathrm{~mm}$ diameter holes separated by 1.0 $\mathrm{mm}$. These had been stored in a polyester acetate envelope filled with $80 \%$ isopropyl alcohol and sterilized using 25kGy of gamma irradiation (Figure $2 \mathrm{E}-\mathrm{F}$ ).

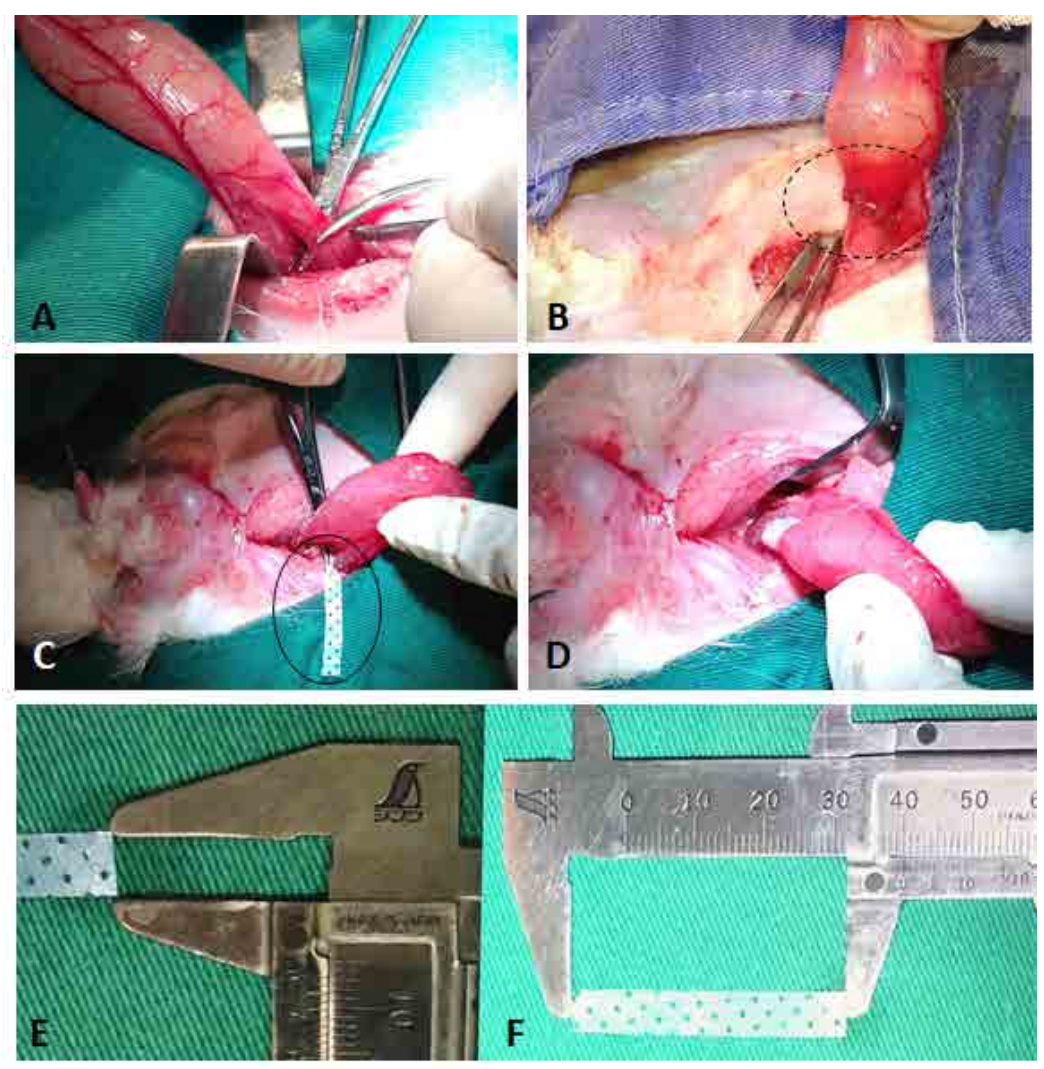

Figure 2 - Surgical technique and cellulosic exopolysaccharide membrane (CEM) measurements. A: Complete section of the urethrovesical transition - urethra (bellow scissors) and urinary bladder (above); B: Rocco's anastomosis with Monofyl ${ }^{\circ}$ Poly - Control group (glycolide-and-caprolactone); C: Rocco's anastomosis with Monofyl $l^{\circ}$ Poly with cellulosic exopolishacaryde membrane (CEM group); D: Final anastomosis aspect; E-F: CEM's dimensions: 4 x $0.6 \mathrm{~cm}$. 
Postoperative care, euthanasia and tissue sample processing

The animals were weighed on the day of surgery (T1), again 7 days after surgery (T2) and before euthanasia (T3). Lethal doses of sodium thiopental were administrated for euthanasia, which occurred 7 and 14 weeks after surgery. During euthanasia all animals were evaluated and classified with respect to the bladder's aspect (normal or bladder distention); turbidity urine level (at surgery and euthanasia), stenosis and adherence presence.

Collection of the urethrovesical anastomosis specimens was performed by means of a large abdominal incision, with the removal, in block, of the abdominal wall with the bladder. Samples were fixed in $10 \%$ buffered formalin and, after fixation, embedded in paraffin, sliced $5 \mu \mathrm{m}$ thick, stained with hematoxylin and eosin and sent for histological and morphometric analysis.

\section{Histological analyzes}

Morphometry of the urethra and urothelium wall thickness

The methodology to measure the urethra and urothelium wall thickness, was the same used by Lima et al. ${ }^{8}$. Briefly, the area was divided into four quadrants to obtain an average of 20 measurements per quadrant. The images were then captured with optical magnification of $4 x$ or $400 x$. The measurements were made using the program Image J45 (National Institute of Health, Bethesda, MD, USA). For both, treated (CEM7 and CEM14) and control groups (C7 and C14), measurement of the thickness of the urethral wall was made starting from the lamina propria, the area in close contact with the urothelium, until the outer muscle layer. The urothelium wall thickness was measured using the above-described methodology from lamina propria to the urothelium-lumen limit.

\section{CEM's integration and host tissue response}

Panoramic histological sections were performed to identify the disposition of CEM and the impact of its integration into the host tissue and around it. Each slide was then classified as follow: (+) mild; (++) moderate; $(+++)$ intense for CEM's cell colonization, amount of GMC, inflammatory infiltrate and angiogenesis.

Angiogenesis density and inflammatory response

Point counting of 630 intersections was used in 15 randomly selected fields for each animal (four to five fields per histological section), for new blood vessels, fibroblasts, giant multinucleated cells (GMCs), macrophages, mononuclear cells (counted as one: lymphocytes and plasma cells), polymorphonuclears, and areas of CEM plus collagen fibers to determine the volume densities of angiogenesis, CEM's cell colonization and inflammatory response.

\section{Statistical analysis}

All variables measured were tested for normality prior to analysis, using the univariate procedure of SigmaPlot 13 . The Student t-test was used to compare continuous variables between the control and CEM group, and comparisons between the time groups were made by one-way ANOVA. $P \leq 0.05$ was considered significant. Data were reported as means and SEM (standard error of the mean) using tables and graphs.

\section{- Results}

Deaths and clinical outcomes

The average surgery time was 51.56 
minutes per animal. By the end of the surgery, all anastomoses were considered good or excellent, and the bladder catheter passage had occurred without resistance. Some catheters were spontaneously expelled between the 2nd and 4th POD (post-operative day), and most were removed on the 7 th POD Five deaths occurred among the 28 operated animals, 3 from the CEM group and 2 from the Control group.

All animals had the aspect of the bladder classified as normal, without stenosis, no change in urine turbidity levels or adherence level (Table 1). Animals' weight was not altered as a result of the surgical procedure.

Table 1 - Clinical aspects.

\begin{tabular}{clccc} 
Groups & Bladder & Stenosis & Turbidity urine level & Adherence level \\
\hline C7 & normal & No & $2+/ 3+$ & Mild adherence \\
C14 & normal & No & $1+/ 3+$ & Mild adherence \\
CEM7 & normal & No & $1+/ 3+$ & CEM well integrated and light adherence \\
CEM14 & normal & No & $2+/ 3+$ & CEM well integrated and light adherence \\
\hline
\end{tabular}

C: Control, $n=5 ; C E M, n=4$. CEM: Cellulose exopolysaccharide membrane. No case of urinary fistula was found.

\section{Histological analysis}

\section{CEM's integration and host tissue response}

The integration patterns were rearranged quantitatively to express mild, moderate and intense levels and are presented in Table 2. The intact urethra was observed, with preservation of its lumen and portions of the CEM encircling it (Figure $3 \mathrm{~A}-\mathrm{B}$ ). Using a higher magnification, it is possible to observe that the CEM is well distributed around the urethra, with an intense number of GMCs (multinucleated giant cells), distributed homogeneously in the area of the CEM; a moderate number of inflammatory cells after 7 weeks (Figure 3C) and a slight amount after 14 weeks (Figure 3D). The CEM was surrounded by connective tissue at both experimental times. Moderate angiogenesis was found in the CEM (close to urethral wall) and in the wall-CEM interface after 7 weeks and intense angiogenesis after 14 weeks. An apparent more pronounced cell colonization was also observed after 14 weeks.

Table 2 - CEM's integration and host tissue response.

\begin{tabular}{cccccc} 
Time & Cell colonization & GMCs & $\begin{array}{c}\text { inflammatory } \\
\text { infiltrate }\end{array}$ & $\begin{array}{c}\text { Tecidual } \\
\text { integration }\end{array}$ & Angiogenesis \\
\hline 7 weeks & ++ & +++ & ++ & $*$ & ++ \\
14 weeks & +++ & +++ & + & $*$ & +++ \\
\hline
\end{tabular}

CEM: Cellulose exopolysaccharide membrane. $\mathrm{n}=3$ / group. GMCs: Multinucleated giant cells; + mild; ++ moderate; +++ intense. * Presence of connective tissue involving the entire prosthesis without fibrous capsule formation. 


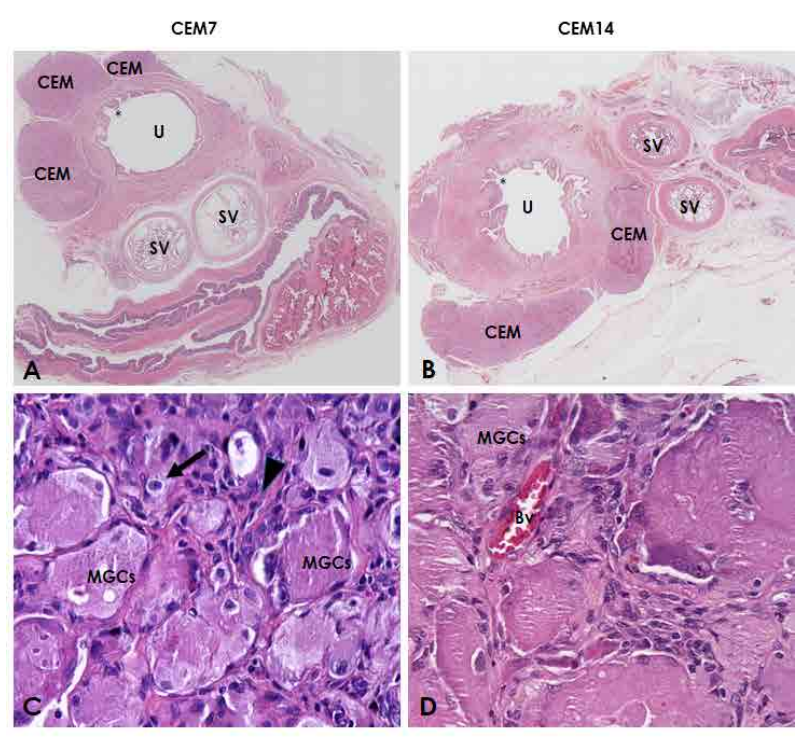

Figure 3 - Histological analysis of CEM's integration and biocompatibility. $\mathbf{A}$ and $\mathbf{B}=$ panoramic cuts (x50), stained with HE to visualize the host tissue response, respectively, after 7 and 14 weeks of CEM's implantation. C and D: x400 magnifications to quantify the angiogenesis and cell density. $C E M=$ cellulosic exopolysaccharide membrane; $\mathrm{Bs}=$ blood vessel; MGCs = multinuclear giant cells; $U$ = urethra; $\mathrm{SV}=$ seminal vesicle; ${ }^{*}=$ urothelium; black arrow = macrophages, black arrowhead = fibroblasts.

Morphometry of urethral and urothelial wall thickness

The thickness of the urethral wall (Figure 4), measured from lamina propria up to the outer edge of the muscular layer, was similar in both groups, C7 and C14 (P=0.713); as well as CEM7 and CEM14 ( $P=0.287)$. That is, the level of tissue integration after CEM's implant at 7 or 14 weeks was the same. However, a greater thickness with a statistical tendency was observed for the membranewall set (WC+CEM14 $\times$ C14), probably an integration between the membrane and the urethral wall $(P=0.077)$. There were no statistical differences in urethral wall thickness plus CEM between 7 and 14 weeks ( $P=0.152)$ or differences in CEM's thickness, also between times $(P=0.856)$.

The urethral epithelium, measured from the lamina propria up to the urothelium-light border, did not change after CEM implantation, since its thickness was not statistically different between the groups.

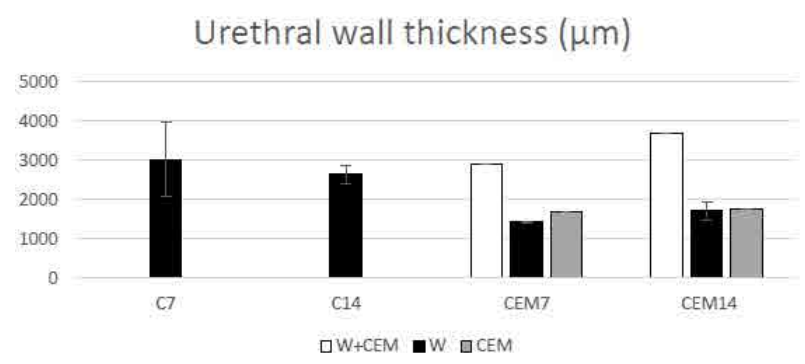

Figure 4 - Urethral wall thickness. Values presented as mean \pm SEM. $W+C E M=$ urethral wall plus CEM thickness; $\mathrm{W}$ : wall; $\mathrm{CEM}=$ cellulosic exopolysaccharide membrane. P-value after t-student test between UW + CEM values at 14 weeks and C14. There were no statistical differences in urethral wall thickness plus CEM between 7 and 14 weeks $(P=0.152)$ or difference in CEM's thickness, also between times $(P=0.856)$.

\section{Angiogenesis density and inflammatory response (\%)}

Angiogenesis, cell density after CEM integration and inflammatory response were calculated by morphometric quantification of different cell types as well as the presence of new blood vessels. No statistical differences were observed as none of the above parameters had been compared when the two experimental times were compared $(P \leq 0.05)$. The data are summarized in Table 3.

Table 3 - Angiogenesis density and inflammatory response (\%).

\begin{tabular}{cccccccc}
\hline Time & BV & Fibrob. & GMCs & Mac. & Mono & Poly & CEM/cf \\
\hline 7 weeks & 0.75 & 1.23 & 31.31 & 27.46 & 6.03 & 0.04 & 33.17 \\
14 weeks & 1.53 & 0.37 & 33.65 & 24.81 & 4.50 & 0.00 & 35.13 \\
P-value & 0.057 & 0.343 & 0.844 & 0.808 & 0.685 & 0.629 & 1.000 \\
\hline
\end{tabular}

P-value after student t-test between 7 and 14 weeks. BV: blood vessels; Fibrob: fibroblasts; GMCs: multinucleated giant cells; Mac: macrophage; Mono: lymphocytes and plasmocyte cells; Poly: polymorphonuclear; CEM/CF: CEM plus collagen fibers. CEM7 and CEM 14: ( $n=3$ /group). 


\section{- Discussion}

The estimate for cancer in Brazil in 2017 indicates the occurrence of about 600.000 new cases. Excluding non-melanoma skin cancer (approximately 180,000 new cases), approximately 420.000 new cases of cancer probably occurred ${ }^{1}$. The epidemiological profile observed resembles that of Latin America and the Caribbean, where prostate cancer (61.000) in men and breast cancer (58.000) in women are the most frequent ${ }^{1}$. The surgery indicated to treat a patient who has detected prostate cancer, when the disease is confined to the prostate and within the limits of the prostate capsule is called radical prostatectomy (RP). That is, RP aims to cure the cancer patient, maintain urinary continence and erectile function. However, RP has several complications (urinary fistulas, bladder neck stenosis, urinary incontinence and prolonged urinary catheter time). The surgery itself causes damage or partial loss of the smooth muscle responsible for involuntary urinary continence, located between the bladder neck the proximal prostatic urethra and external urethral sphincter. These patients are more dependent on the striated sphincter to recover urinary continence in the postoperative period, and therefore its preservation during surgery is critical in this process. On the other hand, bladder neck stenosis is also a recurrent complication, characterized by the narrowing of urethral lumen with devastating consequences and complex treatment. Stenosis usually occurs centripetally, making it difficult to empty the bladder and to pass urine.

For urinary continence after RP to be maintained through preservation of the lumen and external sphincter, askillful and experienced surgeon is needed. In addition, the material used in the surgical technique of urethrovesical anastomosis (posterior neo-urethroplasty) also directly influences the success rate in the postoperative period. According to Sano et $a l^{2}$, the univariate analysis of two anastomosis groups with different suture devices revealed that only the type of suture and the patient's age were significant parameters for stenosis.

Given this, different materials have been used to reduce the incidence of these complications after RP. Fibrin glue and some polymers, such as cyanoacrylate and BioGlue (albumin and glutaraldehyde) have already been studied. According to Flury et $a .^{10}$, the presence of fibrin glue at the anastomosis site seems to facilitate the sealing of the surgical site, thus allowing removal of the JP (Jackson Pratt) cavity drain after 0.8 days and the Foley catheter after 2.35 days of PR. Another material tested by Hruby et al. ${ }^{11}$ in a pig animal model was BioGlue ${ }^{\circ}$, a combination of glutaraldehyde and purified bovine albumin. According to Fürst and Banerjee ${ }^{12}$, the mixture of these components creates cross-links of albuminalbumin and when applied to the tissue, it will create tissue-albumin cross-links. The result is an adhesion that can seal the tissue within a short period of time. However, Hruby et al. did not confirm the advantages of using Bioglue . According to them, the surgical time increased and there was no improvement in suture quality, either at the immediate postoperative evaluation or after 1 week. In the histological evaluation the healing and inflammatory process in the region of the anastomosis was the same, with or without BioGlue . Finally, another tested material is cyanoacrylate, an adhesive available in different chemical forms ranging from ethyl cyanoacrylate (Superglue ${ }^{\circ}$ ) to isobutyl cyanoacrylate and octyl cyanoacrylate (Dermabond ${ }^{\circ}$ ), which is in clinical use. Cyanoacrylate anastomosis requires the application of permanent sutures, a luminal stent and the subsequent application of the adhesive ${ }^{13}$ simple, fast, and available technique for anastomosis in urological, vascular, gynecological, and general surgical procedures. This method may in the future be a good alternative to microsurgery, particularly in centers where facilities are unavailable and the financial implication is unbearable for the 
patient. Cyanoacrylate is an adhesive or glue that is available in different chemical forms ranging from ethylcyanoacrylate (superglue. However, according to Grummet et al. ${ }^{14}$, using a canine animal model, cyanoacrylate seems not to be suitable to be used in large-diameter vesicourethral anastomosis, that is, what is required for radical prostatectomy.

Recently, two studies have used the cellulosic exopolysaccharide, also known as sugarcane biopolymer, as a possible treatment for vesico-urethral reflux and urinary incontinence using rabbit and rat animal models, respectively ${ }^{8,15}$. The biopolymer was injected into the bladders of adult rabbits using a small abdominal incision and compared to the injection of dextran (Dx) microspheres along with hyaluronic acid. According to these researchers, the biopolymer presented a low inflammatory response and better integration with the host tissue than the Dx after long period of observation. Recently, Lima et al. ${ }^{8}$ used an cellulosic exopolysaccharide membrane as a urethral reinforcement in rats, evaluating their integration and remodeling into the receptor tissue. According to the authors, the membrane adhered to the periurethral tissue, integrating with it and inducing the process of tissue remodeling, necessary for urethral strengthening in an animal model. In view of the research cited above, the present work was developed with the objective of evaluating the efficacy of the cellulosic exopolysaccharide membrane (CEM) as a reinforcement for urethrovesical anastomosis.

We therefore opted to analyze the effect of CEM after RP, since complications may be associated with poor surgical technique and/ or the material used. The monofilament suture material used in this project for anastomosis was the surgeon's choice, since laparoscopic or robot-assisted surgeries and the use of special absorbable and synthetic suture materials treated with polyglyconate or polydiaxone such as V-loc ${ }^{\circ}$, Quill ${ }^{\circ}$ and Stratafix ${ }^{\circ}$ would greatly reduce the incidence of complications associated with anastomosis ${ }^{16}$.

To measure the reinforcement provided by the CEM, the thickness of the urethral wall and the urothelium were measured. The biointegration check of CEM was measured according to angiogenesis density and inflammatory reaction. The wall thickness did not alter over time in the control group (7 or 14 weeks) or after 7 weeks comparing groups $C$ with CEM. However, a greater thickness, with statistical tendency, was observed for the membrane-wall group (EP14 x EP + CEM14). According to Lima et al. ${ }^{8}$ there was no change in wall thickness after CEM implantation, even after 8 months of reinforcement. On the other hand, a different study reports a significant structural gain when using SIS (porcine intestinal submucosa) as a urethral coating, simultaneously with artificial sphincter placement ${ }^{17}$. The histological analysis of this periurethral material after three months of implantation showed remnant connective tissue and low inflammatory reaction, strengthening the idea that this matrix would support the growth of new tissue. However, the adverse result found in that study for wall thickness probably occurred due to the low number of animals analyzed for the group. The high incidence of calcification found in the urine of the experimental animal model made this histological analysis unviable. However, we believe that this fact is not particularly relevant. A short time later, Futyma et al. ${ }^{18}$ followed 66 patients with stress urinary incontinence (SUI) and who had undergone Urolastic $^{\circ}$ injections during different followup periods. Urolastic ${ }^{\circ}$ is a urethral filling agent indicated for the treatment of SUI (stress urinary incontinence) with a success rate of up to $68 \%$ after one year of follow-up and only $30 \%$ the small complications related to the injection of the agent ${ }^{19,20}$ Urolastic, in women with stress urinary incontinence (SUI. The authors observed that only $30 \%$ of the patients 
benefited in the long term after the injection of Urolastic ${ }^{\circ}$, however the microscopic analysis of the lumen revealed that there was no significant statistical difference in the rate of inflammation ${ }^{21}$. The main complications associated with the injection found by the authors were: $6.1 \%$ of patients with urethral obstruction and $4.5 \%$ with migration of the material under the urethra into the bladder. In that study, no case of membrane extrusion after implantation was observed. Recently, Ogaya-Pinies et al. ${ }^{22}$ stated that using a porcine urinary bladder extracellular matrix scaffold (UB-ECM) incorporated into the urethrovesical anastomosis and the distal portion of the bladder during SRARP (Salvage RobotAssisted Radical Prostatectomy) resulted in an anastomotic leakage rate of $6.66 \%$ of the patients who received the UB-ECM support and $35.5 \%$ in the control group that did not receive the membrane.

The urothelium also did not undergo any changes after CEM implantation, regardless of the time analyzed. This same result was found by Lima et al. ${ }^{15}$ after injecting cellulosic exopolysaccharide into rabbit bladder. The bladder epithelium was intact, especially in its basal layer and with preservation of the lumen. However, Lima et al. ${ }^{8}$ found a reduction in epithelial thickness in animals that received CEM + silicone tape after 8 months of implantation. According to the author, the decrease may have occurred due to the CEM position (placed between the urethra and the silicone tape), thereby creating a physical barrier and minimizing the inflammatory reaction of host tissue to the silicone.

Finally, the biocompatibility and the biointegration of CEM was evaluated according to the inflammatory response and the rate of vascularization after CEM implantation ${ }^{23-26}$ In the histological analysis, the CEM adhered well to the urethral wall with preservation of its lumen, membrane vascularization and cell colonization, mainly because the presence of multinucleated giant cells (MNGC), fibroblasts, macrophages, mononuclear and polymorphonuclear cells. Biocompatibility begins when inflammatory cells are recruited to the implantation site, followed by the formation of new vessels capable of delivering nutrients for the integration of the implanted material. Afterwards, the inflammatory cells are gradually replaced by fibroblasts, consequently with collagen deposition, but without fibrous capsule formation ${ }^{8,15,27}$. This biocompatibility associated with the absence of toxicity of the cellulosic exopolysaccharide has also recently been confirmed with in vitro tests by Pinto et al. $^{28}$; both experimental ${ }^{4,5}$ and clinical ${ }^{6,7,29}$.

In view of what has been related above, the CEM is established as biocompatible and easy to integrate into the host tissue, mainly due to the formation of blood vessels and the presence of cell colonization. The absence of bladder neck stenosis, even after CEM implantation, further strengthens its application potential. However, it is not possible to conclude that CEM promotes urethral reinforcement, since a decrease in urethral wall thickness was observed after 14 weeks of implantation. Future studies are needed using the same animal model and with different efficacy tests to affirm or rule out the hypothesis of urethral reinforcement after CEM implantation.

\section{- Conclusion}

The absence of extrusion, stenosis or urinary fistula after 14 weeks of urethrovesical anastomosis demonstrates CEM biocompatibility and biointegration with tendency to a thicker wall.

\section{References}

1. Instituto Nacional de Cancer José Alencar Gomes da Silva. INCA. Estimativa 2016. doi: 978-85-7318-283-5.

2. Raza SJ, Field E, Jay C, Eun D, Fumo $M$, $\mathrm{Hu}$ JC, Guru KA. Surgical competency 
for urethrovesical anastomosis during robot-assisted radical prostatectomy: development and validation of the robotic anastomosis competency evaluation. Urology. 2015;85(1):27-32. doi: 10.1016/j. urology.2014.09.017.

3. Trost L, Elliott D. Small intestinal submucosa urethral wrap at the time of artificial urinary sphincter placement as a salvage treatment option for patients with persistent/ recurrent incontinence following multiple prior sphincter failures and erosions. Urology. 2012;79(4):933-8. doi: 10.1016/j. urology.2011.09.003.

4. Silveira RK, Coelho ARB, Pinto FCM, de Albuquerque $\mathrm{AV}$, de Melo Filho DA, de Andrade Aguiar JL. Bioprosthetic mesh of bacterial cellulose for treatment of abdominal muscle aponeurotic defect in rat model. J Mater Sci Mater Med. 2016;27(8):129. doi: 10.1007/s10856-0165744-z.

5. Abreu TC, Lima RP, Souza VSB, Campos Júnior O, Albuquerque AV, Aguiar JL, Andrade ES, Vasconcelos BC. The biopolymer sugarcane as filling material of critical defects in rats. Acta Cir Bras. 2016;31(1):53-8. doi: 10.1590/ S0102-865020160010000008.

6. Vilar FO, Pinto FCM, Albuquerque AV, Martins AG, Araújo LA, Aguiar JL, Lima SV. $A$ wet dressing for male genital surgery: a phase II clinical trial. Int Braz J Urol. 2016;42(6):1220-7. doi: 10.1590/S16775538.IBJU.2016.0109.

7. Silveira FCA, Pinto FCM, Caldas Neto SS, Leal MC, Cesário J, Aguiar JLA. Treatment of tympanic membrane perforation using bacterial cellulose: a randomized controlled trial. Braz J Otorhinolaryngol. 2016;82(2):203-8. doi: 10.1016/j. bjorl.2015.03.015.

8. Lima SVC, Machado MR, Pinto FCM, Lira $\mathrm{MM}$, Albuquerque AV, Lustosa ES, Silva JG, Campos $O \mathrm{Jr}$. A new material to prevent urethral damage after implantation of artificial devices: an experimental study. Int Braz J Urol. 2017;43(2):335-44. doi: 10.1590/S1677-5538.IBJU.2016.0271.

9. Paterson-Beedle M, Kennedy JF, Melo FAD, Lloyd LL, Medeiros V. Cellulosic exopolysaccharide produced from sugarcane molasses by a Zoogloea sp. Carbohydr Polym. 2000;42(4):375-83. doi: 10.1016/S0144-8617(99)00179-4.
10.Flury SC, Starnes DN, Steers WD. Application of fibrin sealant at the urethrovesical anastomosis in robotic assisted radical prostatectomy: does it enable earlier Foley catheter and Jackson-Pratt drain removal? J Robot Surg. 2008;1(4):303-6. doi: 10.1007/ s11701-007-0061-7.

11. Hruby G, Marruffo F, Durak E, Collins S, Herron A, Landman J. Comparison of BioGlue reinforced and standard running sutured vesicourethral anastomoses. Urology. 2006;68(6):1355-9. doi: 10.1016/j. urology.2006.09.032.

12.Fürst W, Banerjee A. Release of glutaraldehyde from an albuminglutaraldehyde tissue adhesive causes significant in vitro and in vivo toxicity. Ann Thorac Surg. 2005;79(5):1522-8. doi: 10.1016/j.athoracsur.2004.11.054.

13. Bot G, Bot K, Ogunranti J, Onah JA, Sule AZ, Hassan I, Dung ED. The use of cyanoacrylate in surgical anastomosis: an alternative to microsurgery. J Surg Tech Case Rep. 2010;2(1):44-8. doi: 10.4103/20068808.63727.

14.Grummet JP, Costello AJ, Swanson DA, Stephens LC, Cromeens DM. Vesicourethral anastomosis with 2-octyl cyanoacrylate adhesive in an in vivo canine model. Urology. 2002;60(5):935-8. doi: 10.1016/ S0090-4295(02)01887-3.

15.Lima SV, de Oliveira Rangel AE, de Melo Lira MM, Pinto FC, Campos Júnior O, Sampaio FJ, de Andrade Aguiar JL. The biocompatibility of a cellulose exopolysaccharide implant in the rabbit bladder when compared with dextranomer microspheres plus hyaluronic acid. Urology. 2015;85(6):1-6. doi:10.1016/j. urology.2015.02.028.

16.Greenberg JA, Goldman RH. Barbed suture: a review of the technology and clinical uses in obstetrics and gynecology. Rev Obstet Gynecol. 2013;6(3-4):107-15. doi: 10.3909/ riog0231.

17. Margreiter M, Farr A, Sharma V, Schauer I, Klingler HC. Urethral buttressing in patients undergoing artificial urinary sphincter surgery. J Urol. 2013;189(5):1777-81. doi: 10.1016/j.juro.2012.11.152.

18. Futyma K, Nowakowski $Ł$, Gałczyński K, Miotła P, Rechberger T. Nonabsorbable urethral bulking agent - clinical effectiveness and late complications rates in the treatment of recurrent stress urinary 
incontinence after 2 years of follow-up. Eur J Obstet Gynecol Reprod Biol. 2016;207:6872. doi: 10.1016/j.ejogrb.2016.10.011.

19.Zajda J, Farag F. Urolastic-a new bulking agent for the treatment of women with stress urinary incontinence: outcome of 12 months follow up. Adv Urol. 2013;2013:724082. doi: 10.1155/2013/724082.

20.Futyma K, Miotła P, Gałczyński K, Baranowski W, Doniec J, Wodzisławska A, Jóźwik $M$, Oniszczuk M, Rechberger T. An open multicenter study of clinical efficacy and safety of urolastic, an injectable implant for the treatment of stress urinary incontinence: one-year observation. Biomed Res Int. 2015;2015:1-5. doi: 10.1155/2015/851823.

21.Assaf A, Abdin F, Elkady A, Gohar M, Abd AlAziz A, Abd Alhady M. Histopathological effects of silicone rubber 'Ovabloc' on the human fallopian tube. Int J Gynaecol Obstet. 1993 Nov;43(2):181-9. PMID: 7905435.

22.Ogaya-Pinies G, Kadakia Y, PalayapalayamGanapathi H, Woodlief T, Jenson C, Syed J, Patel V. Use of scaffolding tissue biografts to bolster vesicourethral anastomosis during salvage robot-assisted prostatectomy reduces leak rates and catheter times. Eur Urol. 2018 Jul;74(1):92-8. doi: 10.1016/j. eururo.2016.10.004.

23.Anderson JM. Biological responses to materials. Annu Rev Mater Res. 2001;31:81110. doi: 10.1146/annurev.matsci.31.1.81.

24.Anderson JM, McNally AK. Biocompatibility of implants: Lymphocyte/macrophage interactions. Semin Immunopathol.
2011;33(3):221-33. doi: 10.1007/s00281011-0244-1.

25.Anderson JM, Rodriguez A, Chang DT. Foreign body reaction to biomaterials. Semin Immunol. 2008;20(2):86-100. doi: 10.1016/j.smim.2007.11.004.

26.Anderson JM. Future challenges in the in vitro and in vivo evaluation of biomaterial biocompatibility. Regen Biomater. 2016;3(2):73-7. doi: 10.1093/rb/rbw001.

27.Silva DB, Aguiar JLA, Marques A, Coelho AR, Rolim Filho EL. Miringoplastia com enxerto livre de membrana de biopolímero da canade-açúcar e fáscia autóloga em Chinchila laniger. An Fac Med Univ Fed Pernamb. 2006;51(1):45-51.

28.Pinto FCM, De-Oliveira ACAX, De-Carvalho RR, Gomes-Carneiro MR, Coelho DR, Lima SVC, Paumgartten FJR, Aguiar JLA. Acute toxicity, cytotoxicity, genotoxicity and antigenotoxic effects of a cellulosic exopolysaccharide obtained from sugarcane molasses. Carbohydr Polym. 2016;137:55660. doi: 10.1016/j.carbpol.2015.10.071.

29. Cavalcanti LM, Pinto FCM, Oliveira GM, Lima SVC, Aguiar JLA, Lins EM. Efficacy of bacterial cellulose membrane for the treatment of lower limbs chronic varicose ulcers: a randomized and controlled trial. Rev Col Bras Cir. 2017;44(1):72-80. doi: 10.1590/0100-69912017001011.

\section{Acknowledgement}

To Sidney Pratt by English version.

\section{Correspondence:}

Salvador Vilar Correia Lima

Departamento de Cirurgia, Centro de Ciências da Saúde, UFPE

Avenida Professor Moraes Rego, 1235

50670-901 Recife - PE Brasil

Tel.: (55 81)2126-3649

urology@salvador.net

Received: Apr 02, 2018

Review: June 05, 2018

Accepted: July 04, 2018
Conflict of interest: none

Financial sources: MCTI, FINEP, FACEPE, and CNPq

\footnotetext{
${ }^{1}$ Research performed at Center of Experimental Surgery, Laboratory of Immunopathology Keizo Asami (LIKA), and Department of Nuclear Energy (DEN), Universidade Federal de Pernambuco (UFPE), Recife-PE, Brazil.
} 